\title{
Estimation of Incident Solar Radiation on the Walls of a Habitat for the Typical Day of April in the Ouagadougou Region in Burkina Faso
}

\author{
Baba MANSARE ${ }^{1}$, Mamadouba CONTE ${ }^{2}$, Yacouba CAMARA ${ }^{3 *}$, Amadou Lamarana BAH ${ }^{4}$ and Drissa OUEDRAOGO \\ ${ }^{1}$ Université Gamal Abdel Nasser de Conakry, Département de Mathématiques, BP 1147, Conakry, Guinée \\ ${ }^{2}$ Institut Supérieur Agronomique et Vétérinaire, Valéry Giscard D'Estaing, Département Energétique et Environnement, \\ BP 131, Faranah, Guinée \\ 3*Institut Supérieur de Technologie de Mamou, Département Energétique, BP 63, Mamou, Guinée \\ ${ }^{4}$ Université Gamal Abdel Nasser de Conakry, Faculté des Sciences, BP 1147, Conakry, Guinée \\ ${ }^{5}$ Université Joseph KI-ZERBO, Laboratoire d'Energies Thermiques Renouvelables, Ouagadougou, Burkina Faso
}

\begin{abstract}
His work aims to develop a mathematical model of incident solar radiation on all the walls of a sloping roof habitat for a typical climate in the Ouagadougou region. Subsequently, we set up a program for the calculations of the essential parameters of illumination and the various components of solar radiation under the Fortran Programming Language and to plot our curves using the Origin software. This work allowed us to estimate the amount of solar flux that each wall of a habitat receives during a day, to know the importance of the orientation of the main facade of the habitat to the south and to find out how often the roof is exposed to solar radiation. The maximum solar radiations observed at the level of the east, west, south and north walls and of the roof are respectively: 513 $\mathrm{W} / \mathrm{m}^{2}, 515 \mathrm{~W} / \mathrm{m}^{2}, 159 \mathrm{~W} / \mathrm{m}^{2}, 114 \mathrm{~W} / \mathrm{m}^{2}$ and $821 \mathrm{~W} / \mathrm{m}^{2}$.
\end{abstract}

Keywords:- Estimate, Incident Radiation, Habitat Wall, Typical Day.

\section{INTRODUCTION}

Solar radiation is the most important energy resource for man and indeed it is an essential factor for human life. Knowing the distribution of solar radiation at a particular geographic location is solar powered appliances; solar energy is clean, abundant, renewable and a sustainable energy resource from the sun reaching the earth in the form of light and heat $[1,2,3]$. In developing countries, solar radiation data is not readily available for lack of data measurement equipment and the techniques involved [4-6]. Solar radiation from the sun is quickly becoming an alternative to other conventional energy sources. Most of the varying types of clean and energetic bass, solar power seems to be the most favored option due to its infinite and nonpolluting nature [7-14].

Radiation is the oldest source of energy; it is the building block for almost all fossil and renewable types. Solar energy is freely available and could be easily harnessed to reduce our dependence on hydrocarbons [1517]. Solar energy is also the most dominant of all renewable energies, it is at the origin of almost all of the energy sources used by man $[18,19,20]$. It is the most fundamental source of renewable energy on the earth's surface, and global solar radiation $(R s)$ plays an important role in a wide range of applications in fields such as meteorology and hydrology $[21,22]$.

The measurement of solar radiation is always a necessary basis for the design of any solar energy conversion device and for a feasibility study of the possible use of solar energy. Measured data is the best, but may not always be available [23-26]. Knowledge of total solar radiation data is essential for researching and lowering the economic viability of systems that use solar energy [27]. The total solar irradiance data is important for the use of solar energy which is in the form of diurnal variation, monthly average daily values, frequency distribution of the number of constant consecutive days in certain month, with insulation less than one certain threshold and the frequency distribution of monthly and annual mean values [28-31]. Precise data on solar radiation are necessary for the design, simulation and good performance of any project involving solar energy (photovoltaic systems, thermal systems, parabolic solar concentrators, etc.). But the low presence of radiometric stations, leads to an insufficient database for a global study of the components of solar radiation [32]. The use of solar energy in sunny countries is an effective tool to compensate for the lack of energy. The interest of such energy is not only economic but also environmental because pollution has become a major problem to which solutions must be found $[33,34]$.

\section{MATERIALS AND METHODS}

\section{* Materials}

\section{$>$ Presentation of the study area}

Burkina Faso is located in the heart of West Africa (Figure 1), between $3{ }^{\circ}$ East longitude and $6^{\circ}$ West longitude and between $9^{\circ}$ and $15^{\circ}$ North latitude. The climate is tropical dry, characterized by an alternation of a dry season lasting eight months in the north, five months in the south and a wet or wintering season ranging from April to October in the south and June to September in the North. 
March and April are the hottest months of the year and December and January the coolest. Burkina Faso is subdivided into three climatic zones (figure 1) which are $[35,36]$ : the Sahelian zone, the Sudano-Sahelian zone and the Sudano-Guinean zone.

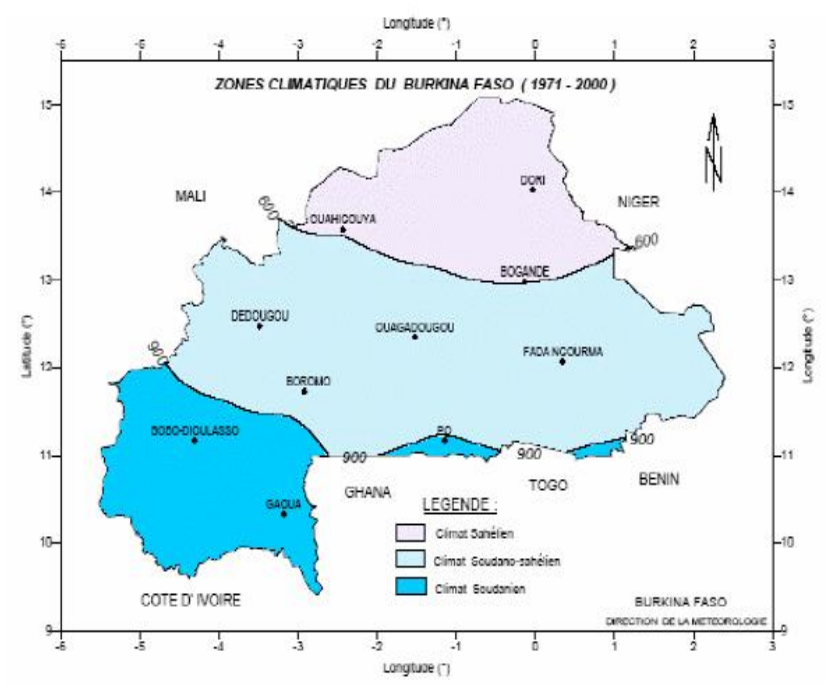

Fig 1:- Burkina Faso climate map

\section{Tools}

The tools that we used for this research are the meteorological data of the typical day of April in the Ouagadougou region represented in figure 2 which represents the most critical month of this region during the 12 typical days. The programming language is Fortran for simulation and the Origin software for plotting curves.

Figure 2 shows the trend in global solar radiation on a horizontal plane $(\mathrm{RGH})$ and in ambient air temperature (TEMP) for the typical day in April.

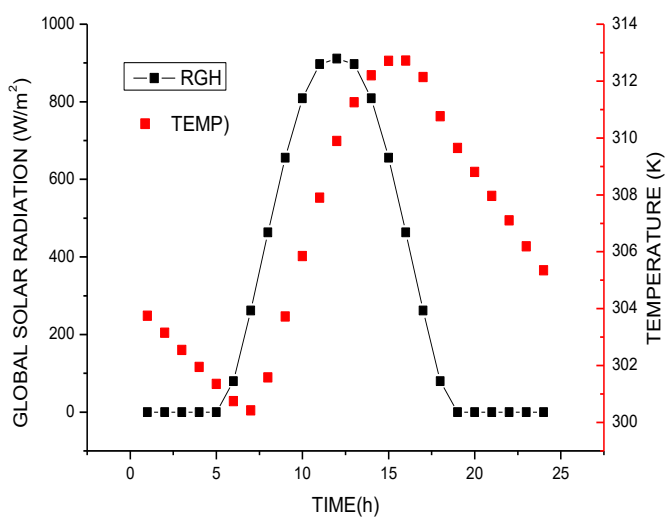

Fig 2: - Global solar radiation and ambient temperature of the typical day in April in the Ouagadougou region

\section{* Methods}

We proceeded to the modeling of the parameters of the lighting in the first place and that of the global radiation and incidents on the walls of a roof habitat inclined by an angle of $30^{\circ}$ in the second step.

\section{Mathematical models of the lighting parameters}

The astronomical formulas established for modeling solar radiation are as follows:

Declination, $\delta$

$\delta=23.45 \operatorname{Sin}\left[360 \cdot \frac{(284+n)}{365}\right]$

Where $\mathrm{n}$ : is the number of days

Hour angle of the sun, $\omega_{r d}$

$$
\omega_{r d}=(T S V-12) \cdot \frac{\pi}{12}
$$

True solar time, TSV

$$
\mathrm{TSV}=\mathrm{TL}-\mathrm{N}+\mathrm{ET}+\left(\frac{\mathrm{LG}}{15}\right)
$$

With :

TL : temps local en heure;

$\mathrm{N}$ : time difference, equal to 0 for Guinea;

ET : equation of time;

LG : longitude of the place

\section{Equation of time, ET}

$E T=9.87 x \operatorname{Sin}\left[720 .\left(\frac{J-81}{365}\right)\right]-7.53 x \operatorname{Cos}\left[720 .\left(\frac{J-81}{365}\right)\right]-1.5 x \operatorname{Sin}\left[360 .\left(\frac{J-81}{365}\right)\right]$

Sun height, $\alpha_{\mathrm{s}}$

$\operatorname{Sin}\left(\alpha_{s}\right)=\operatorname{Cos}(\varphi) \operatorname{Cos}(\delta) \operatorname{Cos}(\omega)+\operatorname{Sin}(\varphi) \operatorname{Sin}(\delta)$

Sun azimuth, $\gamma_{s}$

$\operatorname{Sin}\left(\gamma_{s}\right)=\frac{\operatorname{Cos}(\delta) \operatorname{Sin}(\omega)}{\operatorname{Cos}\left(\alpha_{s}\right)}$

\section{Mathematical models of solar radiation}

Incident solar radiation on any plane

$\operatorname{Cos}(\theta)=\operatorname{Sin} \delta \operatorname{Sin} \varphi \operatorname{Cos} \beta$

$-\operatorname{Sin} \delta \operatorname{Cos} \varphi \operatorname{Sin} \beta \operatorname{Cos} \gamma+\operatorname{Cos} \delta \operatorname{Cos} \varphi \operatorname{Cos} \beta \operatorname{Cos} \omega$

$+\operatorname{Cos} \delta \operatorname{Sin} \varphi \operatorname{Sin} \beta \operatorname{Cos} \gamma \operatorname{Cos} \omega+\operatorname{Cos} \delta \operatorname{Sin} \beta \operatorname{Sin} \gamma \operatorname{Sin} \omega$

For a horizontal plane, ( $\beta=0)$, Eq.7 becomes :

$$
\operatorname{Cos} \theta=\operatorname{Cos} \varphi \operatorname{Cos} \delta \operatorname{Cos} \omega+\operatorname{Sin} \varphi \operatorname{Sin} \delta
$$

\section{Global solar radiation on a horizontal plane}

$$
R_{G H}^{*}=R_{\text {DIRH }}^{*}+R_{\text {DIFH }}^{*}
$$

If the global horizontal radiation is measured, in this case the horizontal direct radiation is worth:

$$
R_{\text {DIRH }}^{*}=R_{G H}^{*}-R_{\text {DIFH }}^{*}
$$


ISSN No:-2456-2165

Diffuse radiation on a horizontal plane

$R_{\text {DIFH }}^{*}=120 x \Gamma x \operatorname{Exp}\left(\frac{-1}{0.4511+\operatorname{Sin}(h)}\right)(11)$

Where $\Gamma:$ is the cloud factor of the sky, it is expressed by the relation:

$$
\Gamma=0.796-0.01 x \operatorname{Sin}\left[\frac{360}{365} x(n+284)\right]
$$

\section{Direct solar radiation on an inclined plane}

$R_{\text {DIRI }}=R_{\text {DIRH }}^{*} x R_{b}$

With $R_{b}$ : the geometric factor and $R_{b} \geq 0$

$R_{b}=\frac{\operatorname{Cos}(\theta)}{\operatorname{Cos}\left(\theta_{z}\right)}=\frac{\operatorname{Cos}(\theta)}{\operatorname{Sin}(h)}=\frac{\operatorname{Sin} \delta \operatorname{Sin}(\Phi-\beta)+\operatorname{Cos} \delta \operatorname{Cos}(\Phi-\beta)+\operatorname{Cos} \omega}{\operatorname{Sin} \Phi \operatorname{Sin} \delta+\operatorname{Cos} \Phi \operatorname{Cos} \delta \operatorname{Cos} \omega}$

\section{Diffuse solar radiation}

$R_{D I F I}=R_{D I F H} \frac{1+\operatorname{Cos} \beta}{2}$

Solar radiation reflected from the ground

$$
R_{R I F L}=R_{G H} x \rho x \frac{1-\operatorname{Cos} \beta}{2}
$$

Where $\rho:$ is the coefficient of reflection of the ground or albedo and whose average value is 0.25

Global solar radiation on an inclined plane

$R_{G I}=\left[R_{D I R H} x R_{b}\right]+\left[R_{D I F H} x \frac{1+\operatorname{Cos} \beta}{2}\right]+\left[R_{G H} x \rho x \frac{1-\operatorname{Cos} \beta}{2}\right]$

\section{RESULTS AND DISCUSSION}

Figure 3 illustrates the graphical representation of global solar radiation $(\mathrm{RGH})$, direct solar radiation $(\mathrm{RDIRH})$ and diffuse solar radiation (RDIFH) on a horizontal plane. In this figure, we see that the global solar radiation is the sum of the other two radiations as stated in the literature at the level of formula 13. The maximum values of these radiations are observed at $12 \mathrm{~h}$ and are respectively 1000 $\mathrm{W} / \mathrm{m}^{2}$, of $950 \mathrm{~W} / \mathrm{m}^{2}$ and $50 \mathrm{~W} / \mathrm{m}^{2}$.

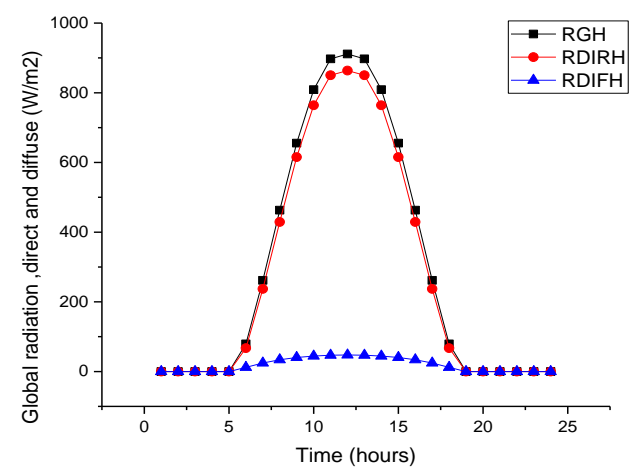

Fig 3: - Global solar radiation, direct and diffuse
Figure 4 shows the profile of global solar radiation on the horizontal plane $(\mathrm{RGH})$, solar radiation incident on the roof (RGIT) and solar radiation incident on the south wall of the habitat (RGIS). In this figure, we notice that the value of the global solar radiation incident on the roof is very close to that of the global solar radiation on the horizontal plane. On the other hand, the solar radiation incident on the south wall is weaker compared to the two preceding radiations, although the south wall is oriented towards the sun. This shows that the roof is the component of the habitat that receives a very large amount of solar flux compared to the other components.

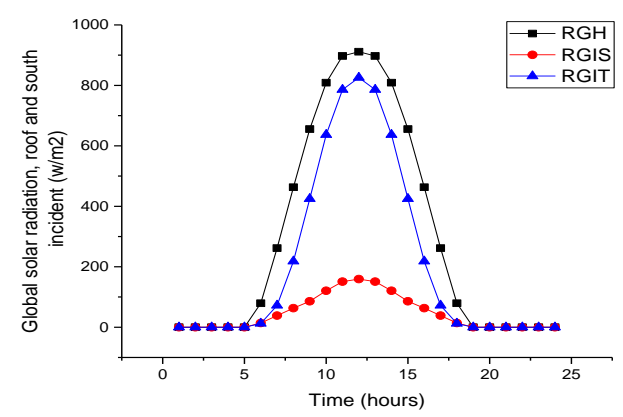

Fig 4: - Global solar radiation, roof incident and south wall incident

FIG. 5 represents the variation graph of the solar radiation incident on the east (RGIE) and west (RGIW) walls of the habitat model. In this figure, we see that the two profiles are symmetrical from noon and the maximum value of solar radiation is observed at 9 a.m. for the west wall and at $3 \mathrm{p} . \mathrm{m}$. for the east wall, which are respectively $513 \mathrm{~W} / \mathrm{m}^{2}$ and $515 \mathrm{~W} / \mathrm{m}^{2}$. This shows that the sun rises in the west and sets in the east.

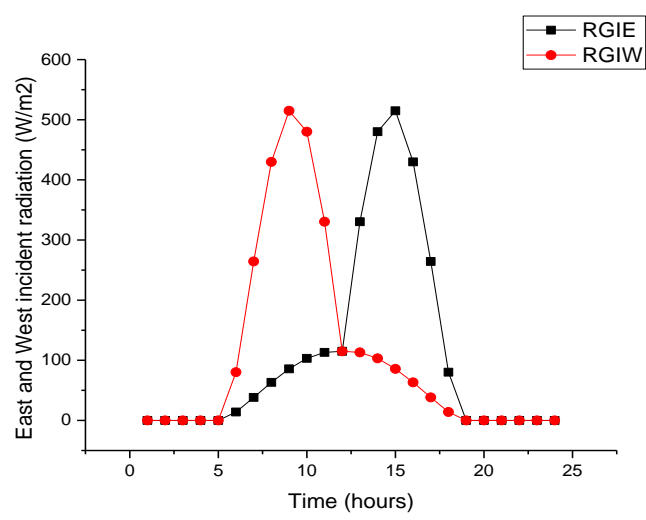

Fig 5: - Incident solar radiation on the east and west wall of the habitat

Figure 6 illustrates the incident solar radiation profile on the south (RGIS) and north (RGIN) walls of the habitat. In this figure, we see that apart from the north wall, it is the south wall which receives the minimum solar flux compared to the other components of the habitat. This shows that to carry out a construction, the main facade of the building must always be oriented towards the south. At sunrise, the flux is maximum on the north side from 6 a.m. to 8 a.m. and from 4 p.m. to 6 p.m., with reasonable amounts compared to 
the maximum value of the solar flux on the south wall. The maximum solar flux values for the south and north walls are observed at noon and are respectively $159 \mathrm{~W} / \mathrm{m}^{2}$ and 114 $\mathrm{W} / \mathrm{m}^{2}$.

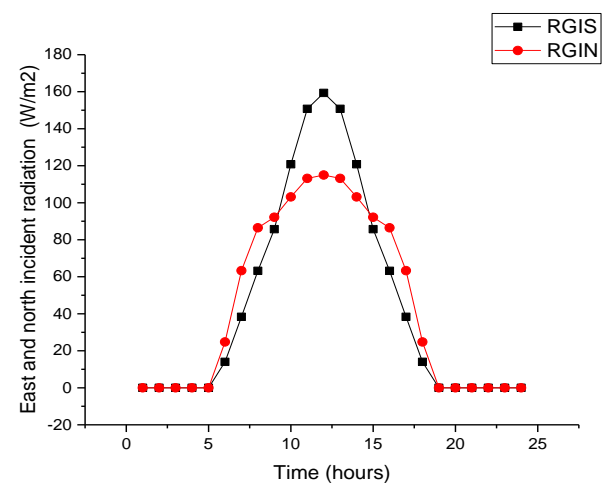

Fig 6: - Incident solar radiation on the south and north wall of the habitat

\section{CONCLUSION}

In this present work, we presented a digital modeling of the essential parameters of illumination, components of solar radiation and incident radiation on the walls of the habitat, whose roof is inclined at an angle of $30^{\circ}$.

Thus, we analyzed the evolution of the direct, diffuse and incident solar radiation profiles on the walls compared to the weather for the typical day in April in the Ouagadougou region in Burkina Faso. These analyzes show us that among all the components of the habitat, the roof is the most exposed to solar radiation with a maximum flux received of the order of $821 \mathrm{~W} / \mathrm{m}^{2}$ observed at noon.

\section{REFERENCES}

[1]. Jam Lu et al. (2018). Global radiation models. A review Journal of Photonic Materials and Technology. pp.26-32

[2]. Mamrata and Sharna. (2012). Comparison of estimated daily global solar radiation using different empirical models. pp.132-137

[3]. Samy et al. (2018). Comparative and Evaluate of Empirical Models for Estimation Global Solar Radiation in Al-Baha, KSA. Journal of Earth Science \& Climatic Change

[4]. Teke et al. (2015). Evaluation and performance comparison of different models for the estimation of solar radiation. Renewable and Sustainable Energy Reviews. pp.1097-1107

[5]. Nik et al. (2012). Monthly mean hourly global radiation estimation. J Solar Energy. pp.379-387

[6]. Sulaiman MY and Umar AB. (2017). A comparative analysis of empirical models for the estimations of monthly mean daily global solar radiation using different climate parameters in Sokoto, Nigeria. International Journal of Marine, Atmospheric and Earth Sciences. pp.1-19
[7]. Okonkwo GN and Nwokoye AOC. (2014). Estimating global solar radiation from temperature data in minna location. European Scientific Journal

[8]. Bolaji BO. (2005). Development and performance evaluation of a Box- Type Absorber Solar Air Collector for Crop Drying. J Food Technology. pp.595-600

[9]. Chiemeka IU. (2008). Estimation of solar radiation at Uturu, Nigeria. Int J Physical Science. pp.126-130

[10]. Duffie JA and Beckman WA. (1991). Solar engineering of thermal processes. (2nd edn) John Wiley and Sons press, New York, USA. p: 944

[11]. El-Sebaii A.A and Trabea AA, (2005), Estimation of global solar radiation on horizontal surfaces over Egypt, Egypt J Solids 28: pp.163-166

[12]. Falayi EO and Rabiu AB, (2008), Prediction of clearness index for some nigerian stations using temperature data, J Sci \& Tech 28: pp.94-101

[13]. Igbal M. (1983). An introduction to solar radiation. (1st edn) Academy Press, New York,USA. p: 408

[14]. Iheonu E.E. (2001). Model for the prediction of average monthly global solar radiation on a horizontal surface for some locations in the tropics using temperature data, Nig. J Solar Energy 9: pp.12-15

[15]. Liu BYH and Jordan RC. (1960). The interrelationship and characteristic distribution of direct, diffuse and total solar radiation. J Solar Energy 4: pp.1-19

[16]. Pereira MC and Rabl A. (1979). The average distribution of solar radiationcorrelations between diffuse and hemispherical and between daily and hourly insolation values. J Solar Energy. pp.155-164

[17]. Gueymard C. (1986). Mean daily averages of beam radiation received by tilted surfaces as affected by the atmosphere. J Solar Energy. pp.261-267

[18]. KALOGIROU S. A. (2009). Solar Energy Engineering: Processes and Systems. (1st ed), Academic Press. pp. 7- 42

[19]. RABL A. (1985). Active solar collectors and their applications. NewYork Oxford, OXFORD UNIVERSITY PRESS. pp.3- 25

[20]. M. Ghodbane et al. (2016). Study and numerical simulation of solar system for air heating. Journal of Fundamental and Applied Sciences

[21]. Almorox et al. (2013). Estimation of daily global solar radiation from measured temperatures at Canada de Luque, C'ordoba, Argentina. Journal of Renewable Energy. vol.60, pp.382-387

[22]. Qingwen et al. (2018). Comparative Analysis of Global Solar Radiation Models in Different Regions of China. Hindawi Advances in Meteorology

[23]. Benkaciali and Gairaa. (2014). Modélisation de l'irradiation solaire globale incidente sur un plan incliné. Revue des Energies Renouvelables Vol. 17. pp. $245-252$

[24]. Garg HP and Garg SN. (1987). Improved correlation of daily and hourly diffuse radiation with global radiation for Indian stations. $\mathrm{J}$ Solar and Wind Technology. pp.113-126

[25]. Gueymard C. (2000). Prediction and performance assessment of mean hourly global radiation. J Solar Energy. pp.285-303 
[26]. Ahmad MJ and Tiwari GN. (2008). Study of models for predicting the mean hourly global radiation from daily summations. Open Environmental Sciences J. pp.6-14

[27]. Jain PC. (1984). Comparison of techniques for the estimation of daily global irradiation and a new technique for the estimation of hourly global irradiation Solar. Wind Technology. pp.123-134

[28]. Oluseyi et al. (2010). Wind energy potential for power generation of a local site in Gusau, Nigeria. Int $\mathbf{J}$ Energy Clean Environ. pp.99-116

[29]. Ajayi et al. (2011). Assessment of wind power potential and wind electricity generation using WECS of two sites in South West, Nigeria. Int J Energy Sci. pp.78-92

[30]. Ajayi et al. (2011). Wind profile characteristics and econometric analysis of wind power generation of a site in Sokoto State, Nigeria. Energy Sci Technol. pp.54-66

[31]. Chegaar M and Chibani A. (2011). A simple method for computing global solar radiation. Rev Energ Ren Chemss. pp.54-66

[32]. Chineke TC. (2008). Equations for estimating global solar radiation in data sparse regions. Renewable Energy. PP.827-831

[33]. Ghodbane et al. (2016). Study and Numerical Simulation of Solar System for Air Heating. Journal of Fundamental and Applied Sciences. Vol. 8.

[34]. Oudrane et al. (2017). Etude et calcul de bilan de la densité du flux solaire pour un simple habitat dans la région d'Adrar. Revue des Energies Renouvelables. Vol. 20. pp.51 - 60

[35]. Idrissa O. (2009). Modélisation et optimization d'une toiture bioclimatique pour la climatisation passive d'un habitat type du Burkina Faso. Thèse de doctorat unique de l'Université de Ouagadougou

[36]. Yacouba C, Xavier C, Sékou C and Cellou K. (2020). Modeling and thermal simulation of a bioclimatic habitat integrating phase-change material for a typical climate of Ouagadougou in Burkina Faso. International Journal of Innovative Science, Engineering \& Technology 